\title{
Reduced-Order Models of Squirrel-Cage Induction Generators for Fixed-Speed Wind Turbines Under Unbalanced Grid Conditions
}

\author{
Alejandro Rolán, Felipe Córcoles López, Santiago Bogarra, Lluis Monjo, and Joaquín Pedra, Member, IEEE
}

\begin{abstract}
This paper develops a study of reduced-order models for squirrel-cage induction generators used in the fixed-speed wind turbines. The squirrel-cage of these generators must be modeled with a double-cage for accuracy purposes. These proposed reduced-order models are valid for unbalanced grid conditions (unsymmetrical faults), which require flux and current decomposition into positive- and negative-sequences. Three reduced-order models are obtained: $\mathbf{R} 2$ model, where the derivative of the positiveand negative-sequences of the stator fluxes are neglected (the usual approach in the literature); R1 model, where the derivative of the negative-sequence of the rotor fluxes are also neglected (proposed model); and R0 model, where all the stator and rotor fluxes are neglected (steady-state electrical model). The analytical models are validated with simulations carried out in the MATLAB and with experimental tests. The results show that $\mathrm{R} 1$ model (proposed model) shows a good performance (similar to the full-order model) under unbalanced conditions.
\end{abstract}

Index Terms-Double-cage induction generator (DGIG), fixedspeed wind turbines, reduced-order of induction generator models, unbalanced grid conditions.

\section{INTRODUCTION}

$\mathbf{T}$ HE FIFTH-ORDER single-cage model is the standard one when modeling induction machines. However, this model fails to represent accurately the behavior of medium- and largesized induction machines because it does not consider the deepbar effect, thus predicting a low starting torque and an inaccurate torque-slip curve, as studied in [1] and [2]. For this reason, the double-cage model should be considered to predict accurately this machine behavior when modeling fixed-speed wind turbines (WTs) [1].

This aside, the complexity of the chosen machine model depends on the required accuracy and on the size of the studied

Manuscript received April 2, 2015; revised August 3, 2015; accepted November 29,2015. This work was supported by the Spanish Ministry of Economy and Competitiveness through Project DPI2011-28021. Paper no. TEC-00242-2015.

A. Rolán is with the Department of Industrial Engineering, Institut Químic de Sarrià, Ramon Llull University, Barcelona 08017, Spain (e-mail: alejandro. rolan@iqs.url.edu).

F. Córcoles López, L. Monjo, and J. Pedra are with the Department of Electrical Engineering, Barcelona School of Industrial Engineering, Polytechnic University of Catalonia, Barcelona 08028, Spain (e-mail: corcoles@ee.upc.edu; lluis.monjo@upc.edu; pedra@ee.upc.edu).

S. Bogarra is with the Department of Electrical Engineering, School of Industrial and Aeronautical Engineering of Terrassa, Polytechnic University of Catalonia, Terrassa-Barcelona 08222, Spain (e-mail: bogarra@ee.upc.edu).

Color versions of one or more of the figures in this paper are available online at http://ieeexplore.ieee.org.

Digital Object Identifier 10.1109/TEC.2015.2504793 power system. In large electrical grids the complexity is reduced by means of the following approach: it is only considered the electrical steady-state of the grid as well as the machine's rotor dynamics [3]. The reduced-order models are obtained by neglecting the derivatives of the stator fluxes and all, some, or any of the rotor fluxes. A comparison of the different reduced-order models is presented in [4].

The classical reduced-order models in the literature, such as [2], [4], [5], appear to be a good approximation to study the machine's dynamic behavior when subject to balanced grid conditions. However, during unbalanced conditions there appear negative-sequences on the machine's variables, which are not considered in these models [6], [7]. In these conditions, the balanced models do not provide information about the oscillations in torque, stator flux, mechanical speed, current, etc., during the event. This means that the classical reducedorder models are not valid under unbalanced grid conditions. An interesting study about the reduced-order models under unbalanced grid conditions is developed in [8], where only the single-cage model for the induction motor is contemplated. The current paper fills this gap, as the double-cage induction generator (DCIG) is considered.

Both positive- and negative-sequences are taken into account in this paper to provide a realistic approach to the machine study under unbalanced grid conditions, mainly during unbalanced voltage sags. The reduced-order models for the DCIG modeling of the generators used in fixed-speed WTs are provided:

1) The R2 model, which neglects the derivative of the positive- and negative-sequences of the stator fluxes (this is the usual approach in the literature).

2) The R1 model, which also neglects the derivative of the negative-sequences of the rotor fluxes (this is the proposed model).

3) The R0 model, which neglects the derivative of both positive- and negative-sequences of stator and rotor fluxes (this is the electrical steady-state model).

It is moreover considered the dynamic equation of the drivetrain (two-mass model) between the WT and the electrical generator. These models are validated by comparison with the full-order DCIG model considering different unbalanced grid conditions. The results show that the proposed reduced-order model (R1 model) can be considered adequate for the unbalanced machine behavior prediction when the network equations are considered algebraic. 


\section{Full-ORder Model FOR THE EleCtricAl EQUATIONS OF THE DCIG}

The induction machine electrical dynamic equations are usually written in Park variables ( $d q$ components) [9]. The $\mathrm{Ku}$ transformation [10] provides a complex notation of the $d q$ components. This transformation is preferred in this paper because the writing is more compact and it facilitates an analytical approach. The relation between the Park and Ku components is given in the Appendix I.

When using the $\mathrm{Ku}$ transformation in an arbitrary reference frame ( $\Psi$ is the transformation angle for the stator variables) and considering the passive sign convention, the electrical equations of the DCIG are:

$$
\begin{aligned}
& {\left[\begin{array}{c}
v_{\mathrm{sf}} \\
0 \\
0
\end{array}\right]=\left[\begin{array}{ccc}
R_{\mathrm{s}} & 0 & 0 \\
0 & R_{1} & 0 \\
0 & 0 & R_{2}
\end{array}\right]\left[\begin{array}{c}
i_{\mathrm{sf}} \\
i_{1 \mathrm{f}} \\
i_{2 \mathrm{f}}
\end{array}\right]} \\
& +\left[\begin{array}{ccc}
\mathrm{j} \omega_{\Psi}+\frac{\mathrm{d}}{\mathrm{d} t} & 0 & 0 \\
0 & \mathrm{j}\left(\omega_{\Psi}-p \omega_{\mathrm{m}}\right)+\frac{\mathrm{d}}{\mathrm{d} t} & 0 \\
0 & 0 & \mathrm{j}\left(\omega_{\Psi}-p \omega_{\mathrm{m}}\right)+\frac{\mathrm{d}}{\mathrm{d} t}
\end{array}\right]
\end{aligned}
$$$$
\times\left[\begin{array}{c}
\lambda_{\mathrm{sf}} \\
\lambda_{1 \mathrm{f}} \\
\lambda_{2 \mathrm{f}}
\end{array}\right]
$$$$
T_{\mathrm{m}}=2 p M \operatorname{Im}\left\{\left(i_{\mathrm{sf}} i_{1 \mathrm{f}}^{*}+i_{\mathrm{sf}} i_{2 \mathrm{f}}^{*}\right)\right\}
$$$$
=2 p \operatorname{Im}\left\{\left(\lambda_{1 \mathrm{f}} i_{1 \mathrm{f}}^{*}+\lambda_{2 \mathrm{f}} i_{2 \mathrm{f}}^{*}\right)\right\}
$$$$
=2 p \operatorname{Im}\left\{\left(i_{\mathrm{sf}} \lambda_{1 \mathrm{f}}^{*}+i_{\mathrm{sf}} \lambda_{2 \mathrm{f}}^{*}\right)\right\}
$$$$
=2 p \frac{M}{\sigma} \operatorname{Im}\left\{\left(\lambda_{\mathrm{sf}} \lambda_{1 \mathrm{f}}^{*}+\lambda_{\mathrm{sf}} \lambda_{2 \mathrm{f}}^{*}\right)\right\}
$$

where

$$
\left[\begin{array}{c}
\lambda_{\mathrm{sf}} \\
\lambda_{1 \mathrm{f}} \\
\lambda_{2 \mathrm{f}}
\end{array}\right]=\left[\begin{array}{ccc}
L_{\mathrm{s}} & M & M \\
M & L_{1} & M_{12} \\
M & M_{12} & L_{2}
\end{array}\right]\left[\begin{array}{c}
i_{\mathrm{sf}} \\
i_{1 \mathrm{f}} \\
i_{2 \mathrm{f}}
\end{array}\right]
$$
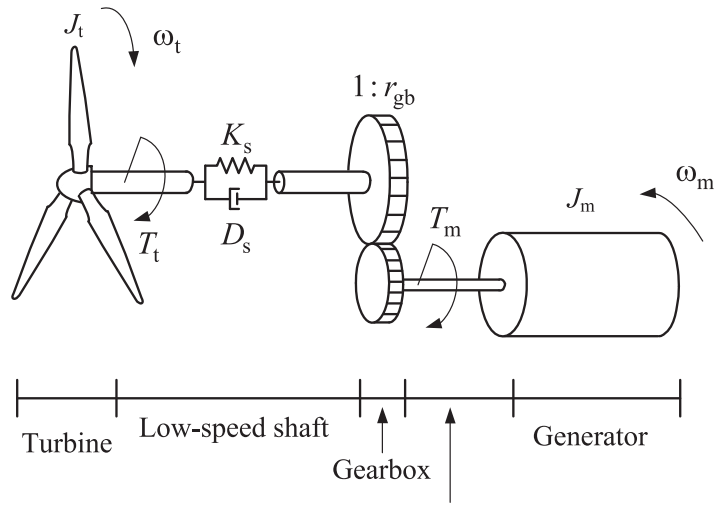

High-speed shaft

Fig. 1. Drive-train of a WT modeled as a two-mass system.

where the subscript s stands for the stator, subscripts 1 and 2 stand for the inner and outer cages of the rotor, respectively, subscript $\mathrm{f}$ stands for the forward component of the Ku transformed variable (see the Appendix I), $\omega_{\Psi}=\mathrm{d} \Psi / \mathrm{d} t$ is the derivative of the transformation angle $\psi, \omega_{\mathrm{m}}$ is the generator speed, $p$ is the number of pole pairs, $T_{\mathrm{m}}$ is the electromagnetic torque and $\sigma=L_{1} L_{2}-M_{12}^{2}$. form. The inverse of (2) provides the currents in function of the fluxes: equation (3) as shown at the bottom of the page. where state-space form, gives:
In this paper, the DCIG model is written in the state-space

$$
D=M^{2}\left(2 M_{12}-L_{1}-L_{2}\right)+L_{s}\left(L_{1} L_{2}-M_{12}^{2}\right) .
$$

The substitution of (3) in (1), and writing of the result in the 106

$$
\frac{\mathrm{d}}{\mathrm{d} t}\left[\begin{array}{c}
\lambda_{\mathrm{sf}} \\
\lambda_{1 \mathrm{f}} \\
\lambda_{2 \mathrm{f}}
\end{array}\right]
$$

$$
\left[\begin{array}{c}
i_{\mathrm{sf}} \\
i_{1 \mathrm{f}} \\
i_{2 \mathrm{f}}
\end{array}\right]=\frac{1}{D}\left[\begin{array}{ccc}
L_{1} L_{2}-M_{12}^{2} & M\left(M_{12}-L_{2}\right) & M\left(M_{12}-L_{1}\right) \\
M\left(M_{12}-L_{2}\right) & L_{\mathrm{s}} L_{2}-M^{2} & M^{2}-L_{\mathrm{s}} M_{12} \\
M\left(M_{12}-L_{1}\right) & M^{2}-L_{\mathrm{s}} M_{12} & L_{\mathrm{s}} L_{1}-M^{2}
\end{array}\right]\left[\begin{array}{c}
\lambda_{\mathrm{sf}} \\
\lambda_{1 \mathrm{f}} \\
\lambda_{2 \mathrm{f}}
\end{array}\right]
$$

$$
\begin{array}{lcc}
a_{11}=\frac{R_{s}\left(M_{12}^{2}-L_{1} L_{2}\right)}{D} & a_{12}=\frac{R_{s} M\left(L_{2}-M_{12}\right)}{D} & a_{13}=\frac{R_{s} M\left(L_{1}-M_{12}\right)}{D} \\
a_{21}=\frac{R_{1} M\left(L_{2}-M_{12}\right)}{D} & a_{22}=\frac{R_{1}\left(M^{2}-L_{\mathrm{s}} L_{2}\right)}{D} & a_{23}=\frac{R_{1}\left(L_{\mathrm{s}} M_{12}-M^{2}\right)}{D} \\
a_{31}=\frac{R_{2} M\left(L_{1}-M_{12}\right)}{D} & a_{32}=\frac{R_{2}\left(L_{s} M_{12}-M^{2}\right)}{D} & a_{33}=\frac{R_{2}\left(M^{2}-L_{\mathrm{s}} L_{1}\right)}{D} .
\end{array}
$$


TABLE I

2.3 MW FIXED-SPEED WT CHARACTERISTICS (FROM [1] AND [16])

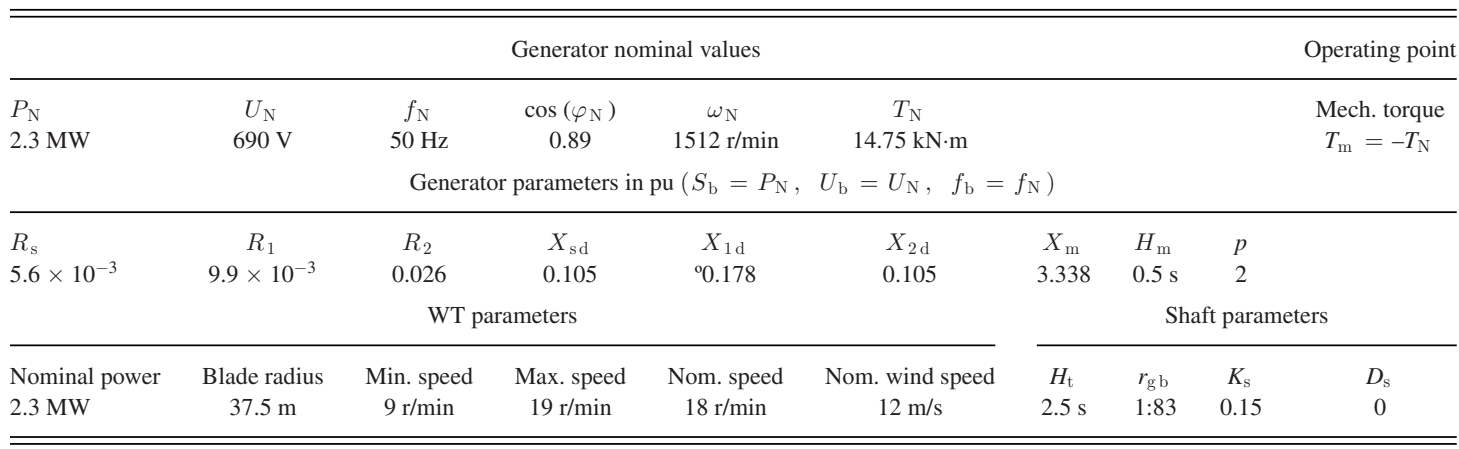

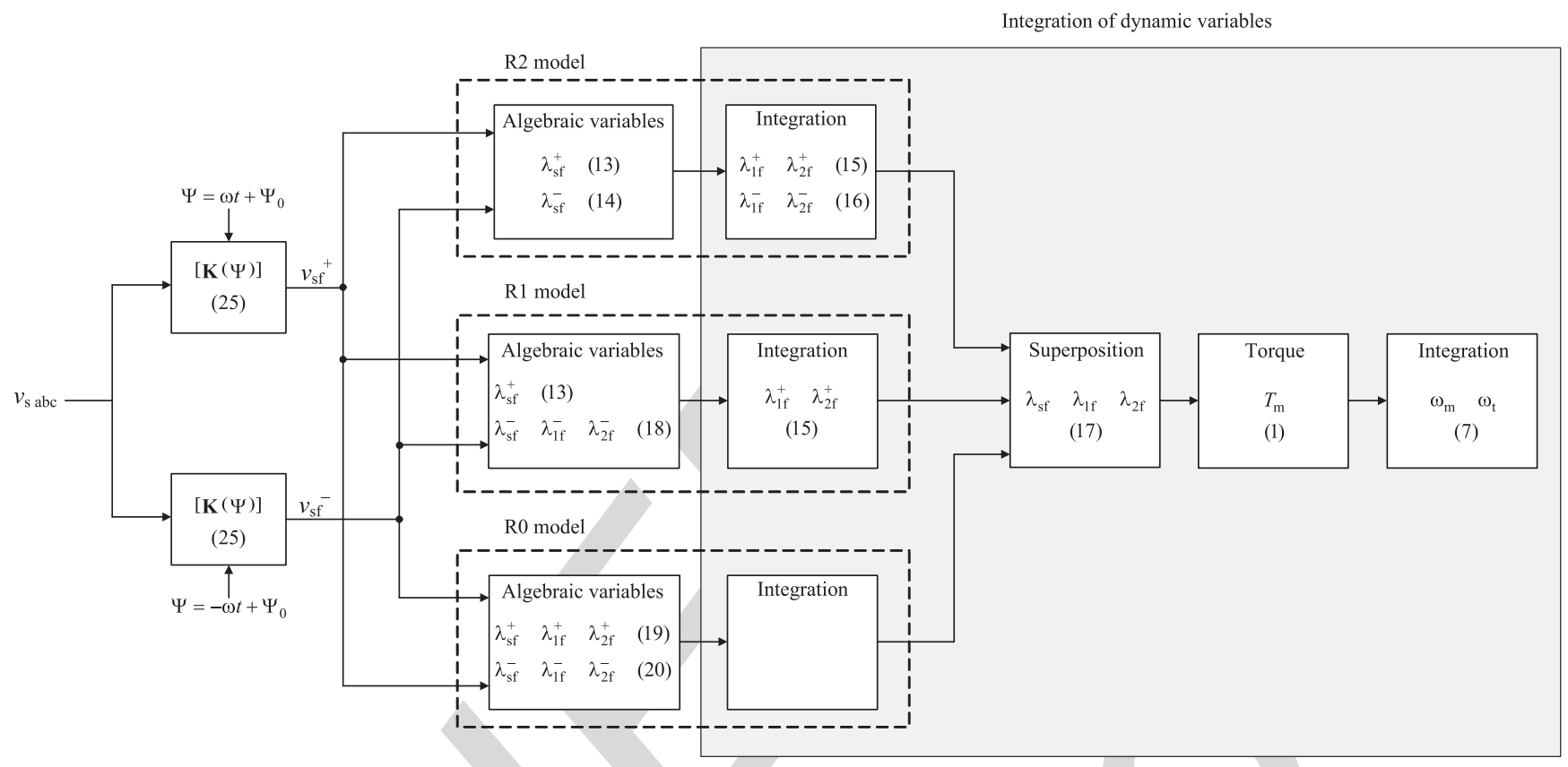

Fig. 2. Block diagram for the computation of the reduced-order model equations: R2 model (usual approach), R1 model (proposed) and R0 model (steady-state).

$$
\times\left[\begin{array}{c}
\lambda_{\mathrm{sf}} \\
\lambda_{1 \mathrm{f}} \\
\lambda_{2 \mathrm{f}}
\end{array}\right]+\left[\begin{array}{c}
v_{\mathrm{sf}} \\
0 \\
0
\end{array}\right]
$$

where equation (6) as shown at the bottom of the previous page.

\section{DRIVE TRAIN MODELING}

The drive train of a WT, i.e., the system located between the turbine blades and the generator, can be modeled as a multi-mass system [11], [12]. In practice, a two-mass model (see Fig. 1) is accurate enough to represent the dynamics of a fixed-speed WT [12], [13]. Considering the motor sign convention and referring all the values to the high-speed shaft (noted with a prime), the mechanical equations of this model are [14]:

$$
\begin{aligned}
J_{\mathrm{t}}^{\prime} \frac{\mathrm{d} \omega_{\mathrm{t}}^{\prime}}{\mathrm{d} t} & =T_{\mathrm{t}}^{\prime}-K_{\mathrm{s}}^{\prime} \gamma-D_{\mathrm{s}}^{\prime}\left(\omega_{\mathrm{t}}^{\prime}-\omega_{\mathrm{m}}\right) \\
J_{\mathrm{m}} \frac{\mathrm{d} \omega_{\mathrm{m}}}{\mathrm{d} t} & =-T_{\mathrm{m}}+K_{\mathrm{s}}^{\prime} \gamma+D_{\mathrm{s}}^{\prime}\left(\omega_{\mathrm{t}}^{\prime}-\omega_{\mathrm{m}}\right)
\end{aligned}
$$

$$
\frac{\mathrm{d} \gamma}{\mathrm{d} t}=\omega_{\mathrm{t}}^{\prime}-\omega_{\mathrm{m}}
$$

where $\omega_{\mathrm{t}}=\omega_{\mathrm{t}}^{\prime} / r_{\mathrm{gb}}$ is the turbine speed $\left(r_{\mathrm{gb}}\right.$ is the gearbox ratio), $\omega_{\mathrm{m}}$ is the generator speed, $J_{\mathrm{t}}=J_{\mathrm{t}}^{\prime} \times r_{\mathrm{gb}}$ is the turbine inertia, $J_{\mathrm{m}}$ is the generator inertia, $K_{\mathrm{s}}=K_{\mathrm{s}}^{\prime} \times r_{\mathrm{gb}}^{2}$ is the shaft stiffness, $D_{\mathrm{s}}=D_{\mathrm{s}}^{\prime} \times r_{\mathrm{gb}}^{2}$ is the shaft damping, $T_{\mathrm{m}}$ is the electromagnetic torque [see (1)] and $T_{\mathrm{t}}=T_{\mathrm{t}}^{\prime} \times r_{\mathrm{gb}}$ is the mechanical torque on the turbine blades, i.e., the wind torque on the turbine blades, which is calculated as [15]:

$$
T_{\mathrm{t}}=\left(0.5 c_{\mathrm{p}} \rho A_{\mathrm{t}} v_{\mathrm{w}}^{3}\right) / \omega_{\mathrm{t}}
$$

where $\rho$ is the air density, $c_{\mathrm{p}}$ is the power coefficient of the WT, 124 $v_{\mathrm{w}}$ is the wind speed and $A_{\mathrm{t}}$ is the area swept by the blades.

\section{FIXED-SPEED WT CHARACTERISTICS}

The generator parameters of the studied 2.3 MW fixed-speed WT have been obtained from [1] and the WT parameters from [16]. All this data is shown in Table I. The fixed-speed WT is 

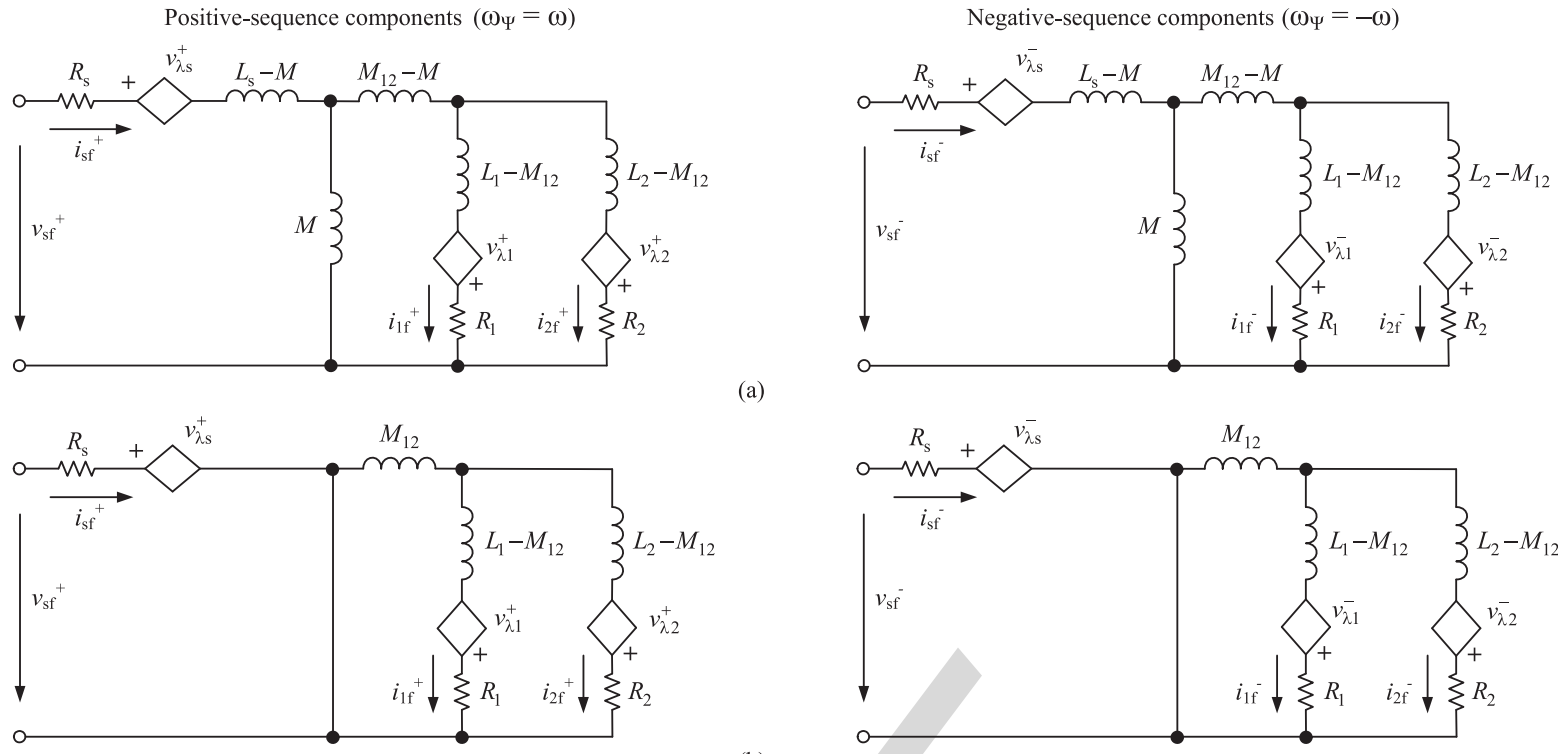

(a)

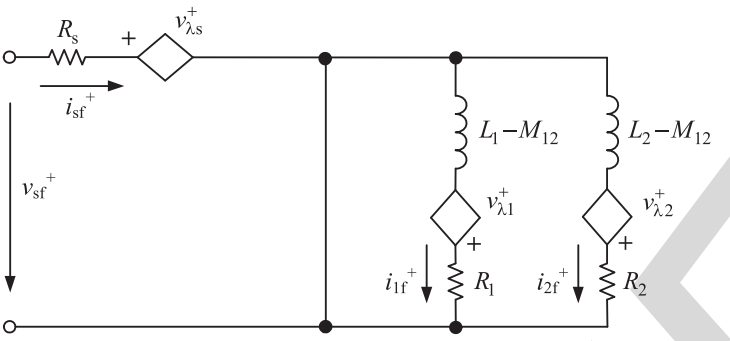

(b)
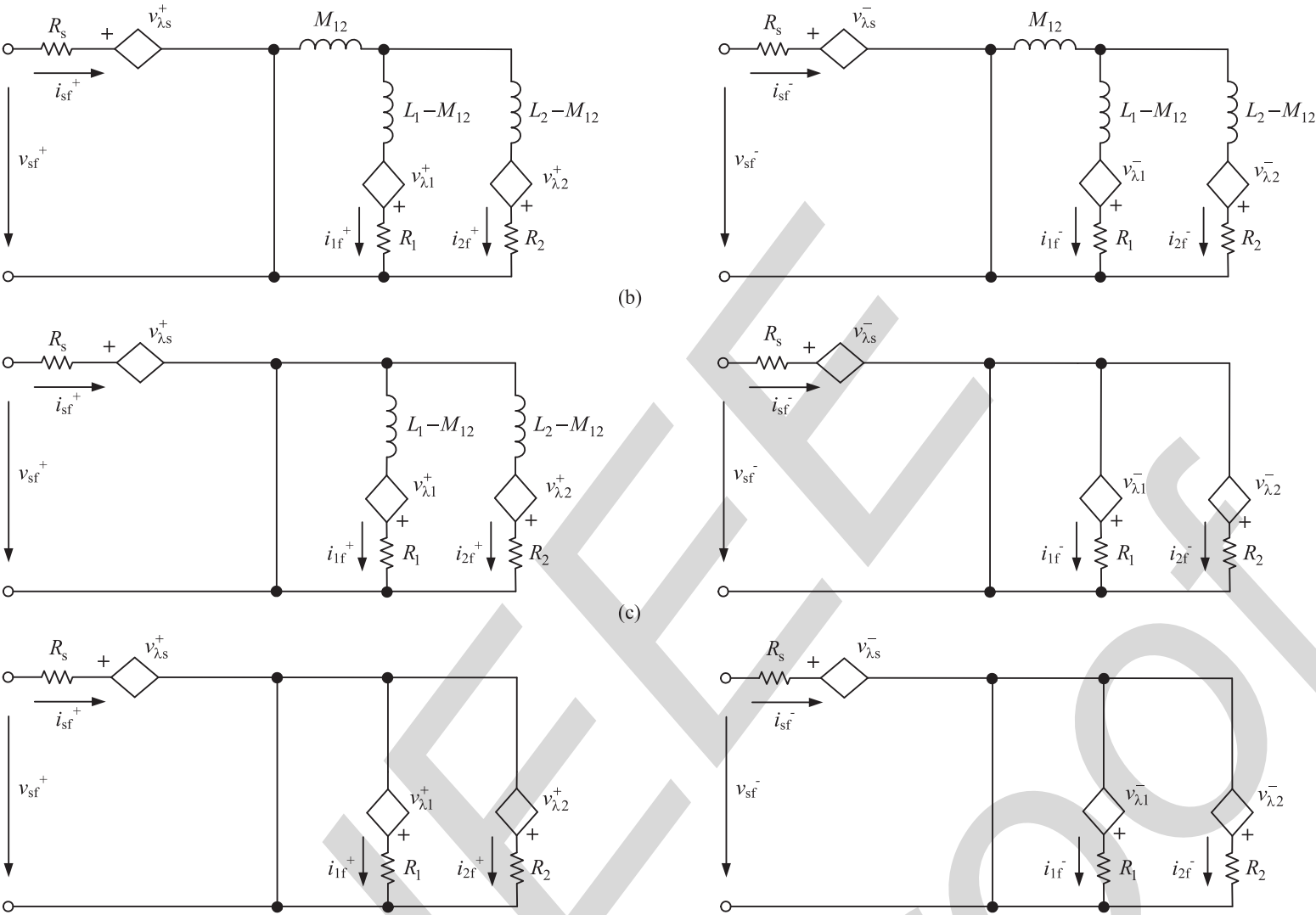

(c)

(d)

$$
\begin{array}{lll}
v_{\lambda \mathrm{s}}^{+}=\mathrm{j} \omega_{\Psi} \lambda_{\mathrm{sf}}^{+} & v_{\lambda 1}^{+}=\mathrm{j}\left(\omega_{\Psi}-p \omega_{\mathrm{m}}\right) \lambda_{1 \mathrm{f}}^{+} & v_{\lambda 2}^{+}=\mathrm{j}\left(\omega_{\Psi}-p \omega_{\mathrm{m}}\right) \lambda_{2 \mathrm{f}}^{+} \\
v_{\lambda \mathrm{s}}^{-}=\mathrm{j} \omega_{\Psi} \lambda_{\mathrm{sf}}^{-} & v_{\lambda 1}^{-}=\mathrm{j}\left(\omega_{\Psi}-p \omega_{\mathrm{m}}\right) \lambda_{1 \mathrm{f}}^{-} & v_{\lambda 2}^{-}=\mathrm{j}\left(\omega_{\Psi}-p \omega_{\mathrm{m}}\right) \lambda_{2 \mathrm{f}}^{-}
\end{array}
$$

Fig. 3. Equivalent circuits of the DCIG under unbalanced grid conditions. (a) Full-order model, (b) R2 model (usual approach), (c) R1 model (proposed) and (d) R0 model (steady-state).

assumed to be operating at its rated torque, i.e., the wind torque on the turbine blades equals the rated torque $\left(T_{\mathrm{t}}=T_{\mathrm{N}}\right)$. It is also assumed constant during the studied grid event.

\section{REDUCED-ORDER MODELS FOR THE ELECTRICAL}

\section{EQUATIONS OF THE DCIG UNDER UNBALANCED CONDITIONS}

\section{A. Positive- and Negative-Sequences}

The steady-state negative-sequence voltages produced by unsymmetrical faults are seen as a double pulsation voltage in the synchronous reference frame. Then, two reference frames can be considered: the first one rotates at the stator voltage pulsation $\omega$ (for the positive-sequence) and the other one rotates at $-w$ (for the negative-sequence), where $\omega=2 \pi f$ is the pulsation 141 of the grid voltages ( $f$ is their frequency). For this reason, the 142 DCIG model in (5) must be applied for the positive-sequence, 143 considering $\omega_{\Psi}=w$ and for the negative-sequence, considering 144 $\omega_{\Psi}=-w$.

The sequence components for all the machine variables are: 146 $v_{\mathrm{sf}}^{+}, v_{\mathrm{sf}}^{-}, \lambda_{\mathrm{sf}}^{+}, \lambda_{\mathrm{sf}}^{-}, \lambda_{1 \mathrm{f}}^{+}, \lambda_{1 \mathrm{f}}^{-}, \lambda_{2 \mathrm{f}}^{+}, \lambda_{2 \mathrm{f}}^{-}$, where the superscripts + and 147 - stand for the positive- and negative-sequences, respectively. 148

It should be noted that at constant speed, the system of dy- 149 namic equations (5) is linear. Thus, the superposition principle 150 can be applied for the positive- and negative-sequences:

$$
x_{\mathrm{f}}=\sqrt{3 / 2}\left(x^{+} \mathrm{e}^{\mathrm{j} \omega_{\Psi} t}+x^{-} \mathrm{e}^{-\mathrm{j} \omega_{\Psi} t}\right) \mathrm{e}^{-\mathrm{j} \Psi},
$$



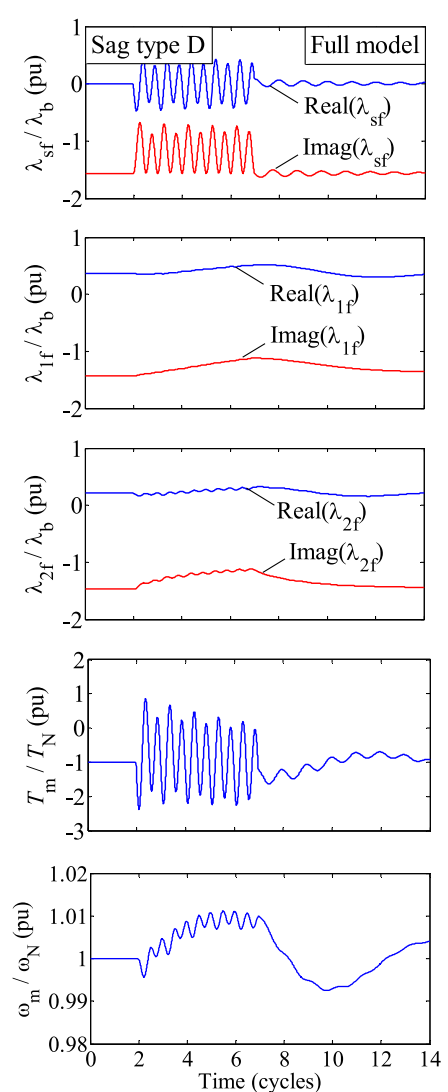

(a)
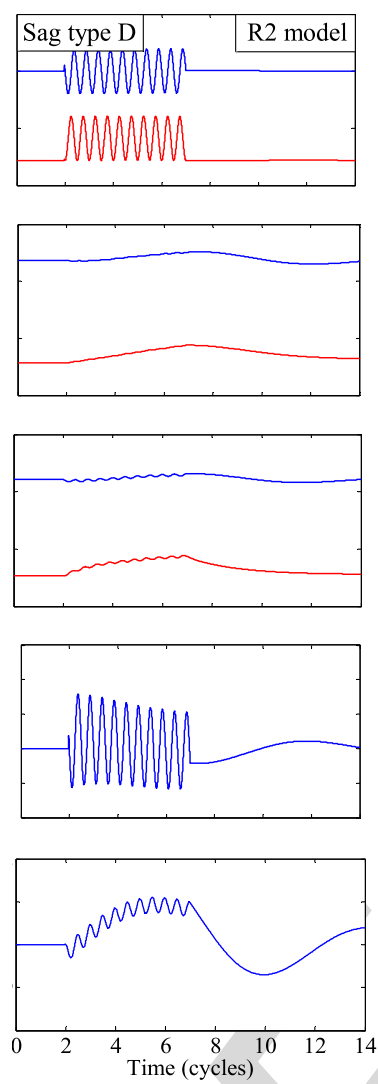

(b)
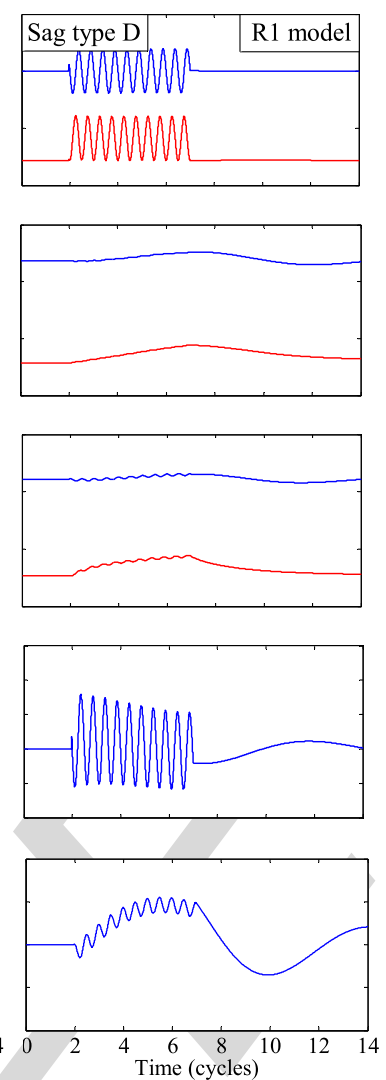

(c)
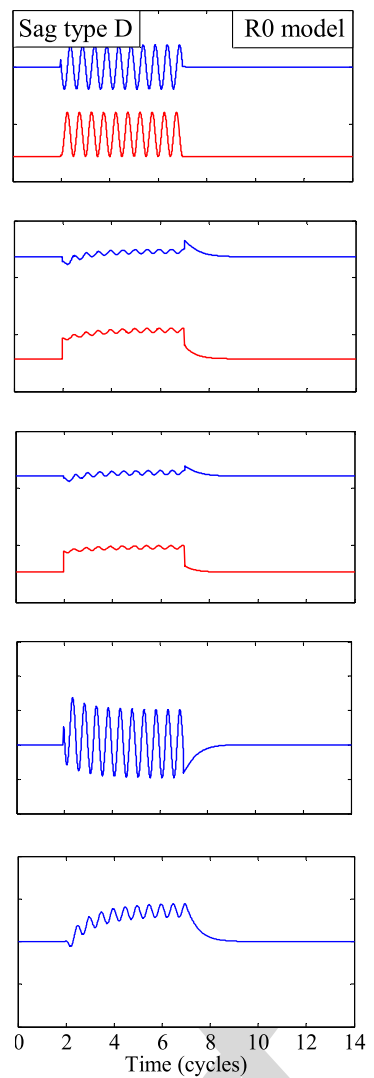

(d)

Fig. 4. 2.3 MW fixed-speed WT equipped with DCIG under unsymmetrical voltage sag type D: transformed stator flux $\left(\lambda_{\mathrm{sf}}\right)$, transformed rotor fluxes $\left(\lambda_{1 \mathrm{f}}\right.$ and $\lambda_{2 \mathrm{f}}$ ), electromagnetic torque ( $\left.T_{\mathrm{m}}\right)$ and mechanical speed $\left(\omega_{\mathrm{m}}\right)$. (a) Full-order model, (b) R2 model (usual approach), (c) R1 model (proposed), and (d) R0 model (steadystate).Sag characteristics: $h=0.5$ and $\Delta t=5$ cycles.

where $x_{\mathrm{f}}$ represents the forward component of the transformed variable (voltage, current or flux), the subscripts + and - stand for the positive- and negative-sequences of the transformed variable, $\omega_{\Psi}$ is the pulsation of a generic reference frame and $\Psi$ is the transformation's angle. If the synchronous reference frame is considered, then $\omega_{\Psi}=w$ (where $\omega=2 \pi f$ is the pulsation of the grid voltages and $f$ is their frequency), and $\Psi=\omega t+\Psi_{0}$, (where $\Psi_{0}$ is the transformation's initial angle). Then, (9) can be rewritten as (see equation (26) in the Appendix I):

$$
x_{\mathrm{f}}=\sqrt{3 / 2}\left(x^{+}+x^{-} \mathrm{e}^{-\mathrm{j} 2 \omega t}\right) \mathrm{e}^{-\mathrm{j} \Psi_{0}} .
$$

\section{B. Considerations Regarding the Induction Generator Models Under Unbalanced Grid Conditions}

The full-order model of the induction generator will respond properly to both balanced and unbalanced grid conditions. However, due to the assumption of constant quantities in steady-state, the reduced-order models are valid only for balanced conditions [8]. Then, the superposition principle (10) must be applied for both positive- and negative-sequences of the machine's variables.

The idea explained above, which was applied in [8] to the single-cage induction machine, is used in this paper to provide reduced-order models for the DCIG under unbalanced grid conditions. Then, the electrical equations of the full-order model of the DCIG (5) can be applied to both positive- and negative- 174 sequences:

$$
\begin{aligned}
& \frac{\mathrm{d}}{\mathrm{d} t}\left[\begin{array}{c}
\lambda_{\mathrm{sf}}^{+} \\
\lambda_{1 \mathrm{f}}^{+} \\
\lambda_{2 \mathrm{f}}^{+}
\end{array}\right]=\left[\begin{array}{ccc}
a_{11}-\mathrm{j} \omega & a_{12} & a_{13} \\
a_{21} & a_{22}-\mathrm{j} s \omega & a_{23} \\
a_{31} & a_{32} & a_{33}-\mathrm{j} s \omega
\end{array}\right] \\
& \times\left[\begin{array}{c}
\lambda_{\mathrm{sf}}^{+} \\
\lambda_{1 \mathrm{f}}^{+} \\
\lambda_{2 \mathrm{f}}^{+}
\end{array}\right]+\left[\begin{array}{c}
v_{\mathrm{sf}}^{+} \\
0 \\
0
\end{array}\right] \\
& \begin{aligned}
\frac{\mathrm{d}}{\mathrm{d} t}\left[\begin{array}{c}
\lambda_{\mathrm{sf}}^{-} \\
\lambda_{1 \mathrm{ff}}^{-} \\
\lambda_{2 \mathrm{f}}^{-}
\end{array}\right]= & {\left[\begin{array}{ccc}
a_{11}+\mathrm{j} \omega & a_{12} & a_{13} \\
a_{21} & a_{22}+\mathrm{j} s \omega & a_{23} \\
a_{31} & a_{32} & a_{33}+\mathrm{j} s \omega
\end{array}\right] } \\
& \times\left[\begin{array}{c}
\lambda_{\mathrm{sf}}^{-} \\
\lambda_{1 \mathrm{f}}^{-} \\
\lambda_{2 \mathrm{f}}^{-}
\end{array}\right]+\left[\begin{array}{c}
v_{\mathrm{sf}}^{-} \\
0 \\
0
\end{array}\right]
\end{aligned}
\end{aligned}
$$

where $s=\left(\omega-p \omega_{\mathrm{m}}\right) / \omega$ is the machine's mechanical slip ( $p$ is 176 the number of pole pairs).

In order to solve the above two differential equations it is assumed that in each integration step the grid voltages (stator voltages) are sinusoidal (but unbalanced) and the generator 

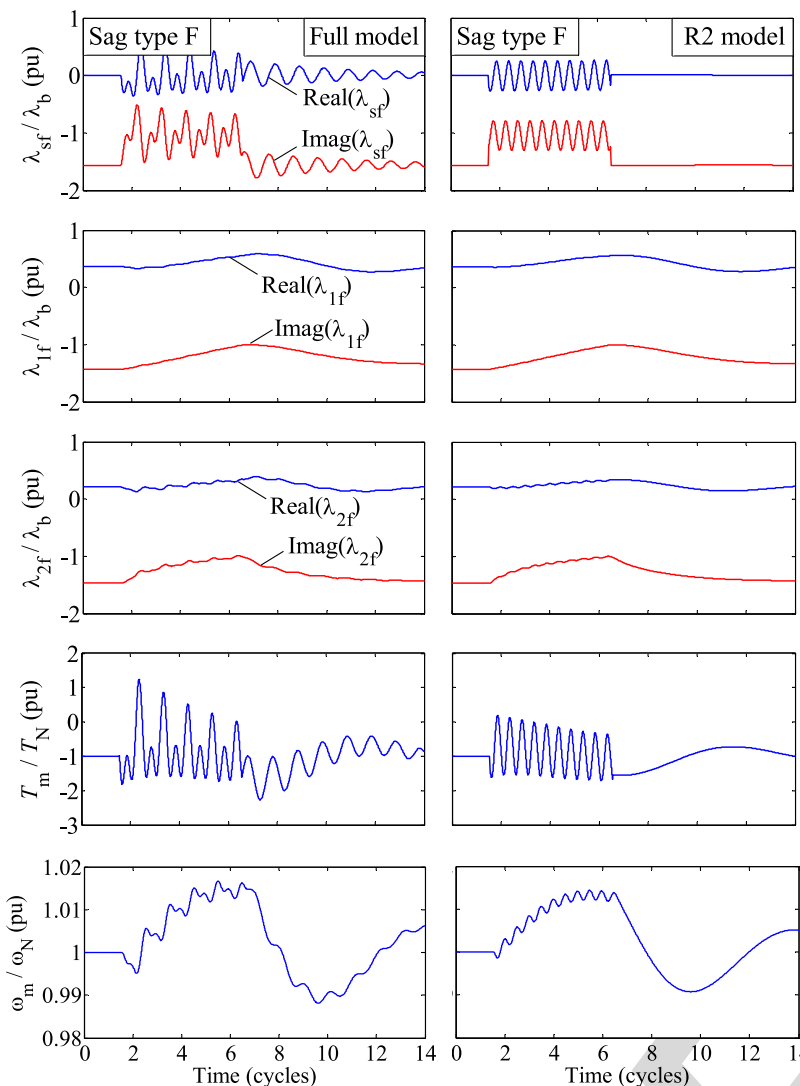

(a)

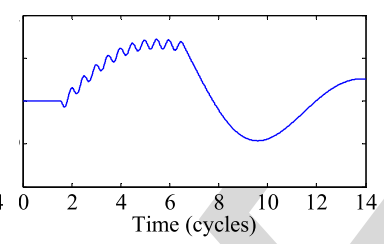

(b)
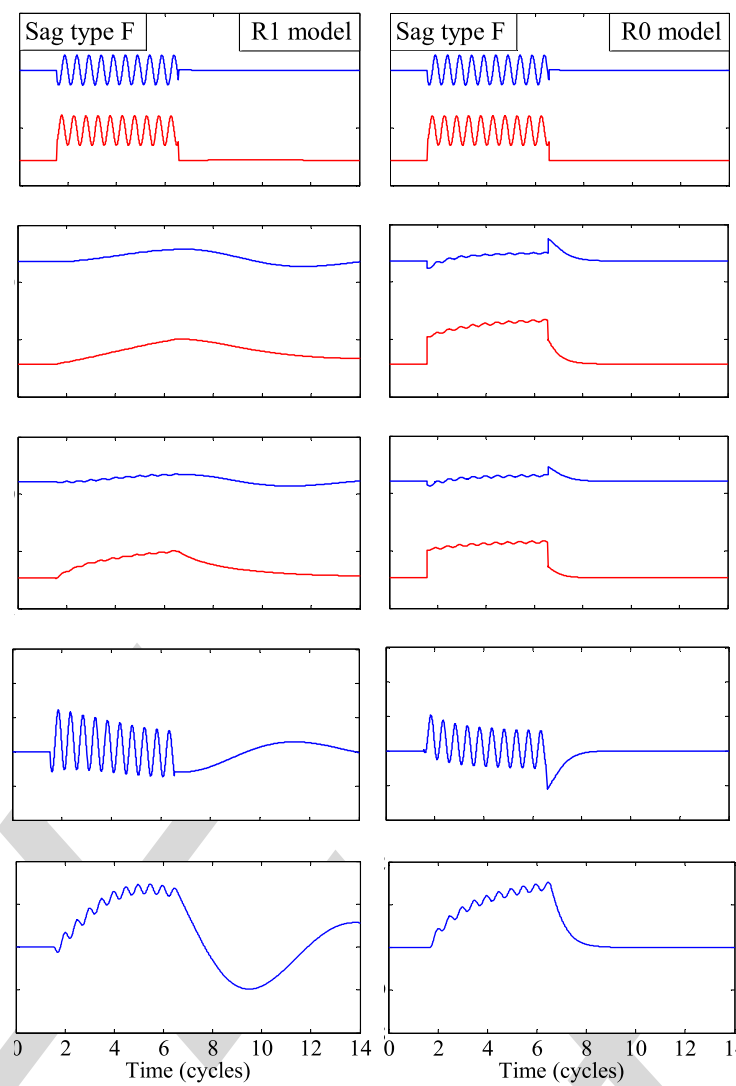

(c)

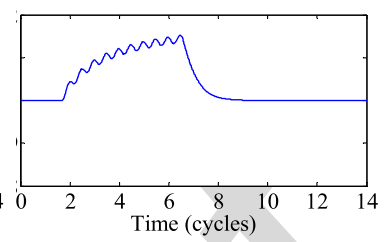

(d)

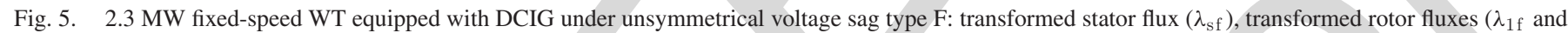

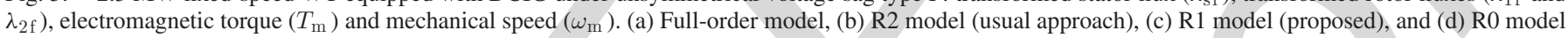
(steady state). Sag characteristics: $h=0.5$ and $\Delta t=5$ cycles.

The remaining fluxes, $\lambda_{1 \mathrm{f}}^{+}, \lambda_{1 \mathrm{f}}^{-}, \lambda_{2 \mathrm{f}}^{+}, \lambda_{2 \mathrm{f}}^{-}$, are obtained by integration of the last two differential equations in (11) and in (12):

$$
\begin{aligned}
\frac{\mathrm{d}}{\mathrm{d} t}\left[\begin{array}{c}
\lambda_{1 \mathrm{f}}^{+} \\
\lambda_{2 \mathrm{f}}^{+}
\end{array}\right]= & {\left[\begin{array}{cc}
a_{22}-\mathrm{j} s \omega & a_{23} \\
a_{32} & a_{33}-\mathrm{j} s \omega
\end{array}\right]\left[\begin{array}{l}
\lambda_{1 \mathrm{f}}^{+} \\
\lambda_{2 \mathrm{f}}^{+}
\end{array}\right] } \\
& +\left[\begin{array}{l}
a_{21} \\
a_{31}
\end{array}\right] \lambda_{\mathrm{sf}}^{+}
\end{aligned}
$$

\section{Rl Model for the Electrical Equations (Proposed Model)}

Simplification: in this model the transients of the negative- 197 sequences of both inner and outer cage are also neglected. 198 Then, $\frac{\mathrm{d}}{\mathrm{d} t} \lambda_{\mathrm{sf}}^{+}=\frac{\mathrm{d}}{\mathrm{d} t} \lambda_{\mathrm{sf}}^{-}=\frac{\mathrm{d}}{\mathrm{d} t} \lambda_{1 \mathrm{f}}^{-}=\frac{\mathrm{d}}{\mathrm{d} t} \lambda_{2 \mathrm{f}}^{-}=0$. Note that all of the 199 negative-sequence fluxes are algebraic, and they are calculated 200 from (12) as follows:

$$
\left[\begin{array}{c}
\lambda_{\mathrm{sf}}^{-} \\
\lambda_{1 \mathrm{f}}^{-} \\
\lambda_{2 \mathrm{f}}^{-}
\end{array}\right]=-\left[\begin{array}{ccc}
a_{11}+\mathrm{j} \omega & a_{12} & a_{13} \\
a_{21} & a_{22}+\mathrm{j} s \omega & a_{23} \\
a_{31} & a_{32} & a_{33}+\mathrm{j} s \omega
\end{array}\right]^{-1}\left[\begin{array}{c}
v_{\mathrm{sf}}^{-} \\
0 \\
0
\end{array}\right] .
$$


TABLE II

PARAmeters of the Tested ThreE-Phase SQUiRREL-CAGE DCIG

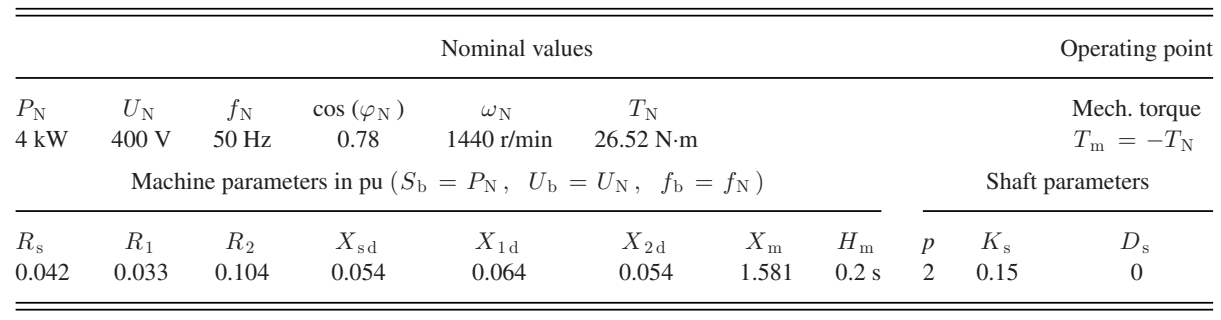

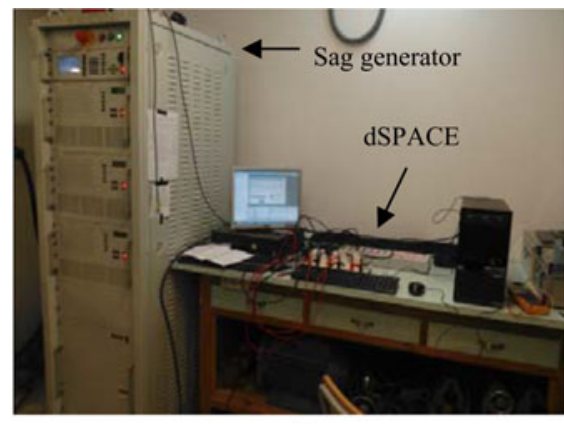

(a)

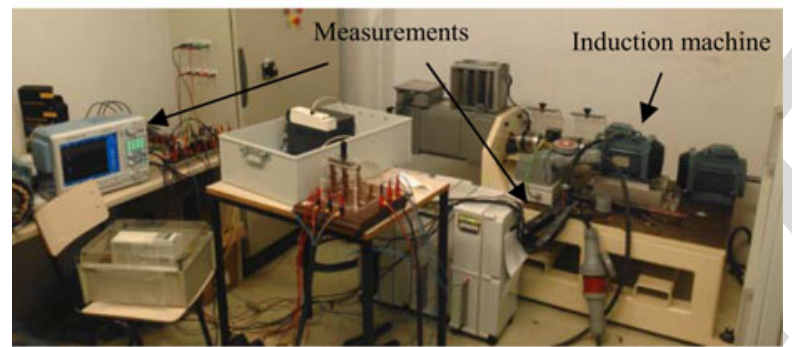

(b)

Fig. 6. Experimental setup used to test the $4 \mathrm{~kW}$ three-phase squirrel-cage induction machine. (a) Sag generator (programmable voltage source of Spitzenberger) and dSPACE (DS1104 of Texas Instruments), and (b) induction machine and measuring devices.
The fluxes $\lambda_{1 \mathrm{f}}^{+}$and $\lambda_{2 \mathrm{f}}^{+}$are obtained again by integration of (15) and $\lambda_{\mathrm{sf}}^{+}$is calculated by (13). Finally, according to (10), the transformed stator and rotor fluxes are given by (17).

\section{E. RO Model for the Electrical Equations (Steady-State)}

Simplification: the transients of all the machine's fluxes are neglected (steady-state model). Thus, only the mechanical transient is considered. Then:

$\frac{\mathrm{d}}{\mathrm{d} t} \lambda_{\mathrm{sf}}^{+}=\frac{\mathrm{d}}{\mathrm{d} t} \lambda_{\mathrm{sf}}^{-}=\frac{\mathrm{d}}{\mathrm{d} t} \lambda_{1 \mathrm{f}}^{+}=\frac{\mathrm{d}}{\mathrm{d} t} \lambda_{1 \mathrm{f}}^{-}=\frac{\mathrm{d}}{\mathrm{d} t} \lambda_{2 \mathrm{f}}^{+}=\frac{\mathrm{d}}{\mathrm{d} t} \lambda_{2 \mathrm{f}}^{-}=0 . \quad$ By doing this simplification in (11) and (12), we can calculate all the algebraic fluxes:

$$
\begin{aligned}
{\left[\begin{array}{c}
\lambda_{\mathrm{sf}}^{+} \\
\lambda_{1 \mathrm{f}}^{+} \\
\lambda_{2 \mathrm{f}}^{+}
\end{array}\right]=} & -\left[\begin{array}{ccc}
a_{11}-\mathrm{j} \omega & a_{12} & a_{13} \\
a_{21} & a_{22}-\mathrm{j} s \omega & a_{23} \\
a_{31} & a_{32} & a_{33}-\mathrm{j} s \omega
\end{array}\right]^{-1} \\
& \times\left[\begin{array}{c}
v_{\mathrm{sf}}^{+} \\
0 \\
0
\end{array}\right]
\end{aligned}
$$

$$
\begin{aligned}
{\left[\begin{array}{c}
\lambda_{\mathrm{sf}}^{-} \\
\lambda_{1 \mathrm{f}}^{-} \\
\lambda_{2 \mathrm{f}}^{-}
\end{array}\right]=} & -\left[\begin{array}{ccc}
a_{11}+\mathrm{j} \omega & a_{12} & a_{13} \\
a_{21} & a_{22}+\mathrm{j} s \omega & a_{23} \\
a_{31} & a_{32} & a_{33}+\mathrm{j} s \omega
\end{array}\right]^{-1} \\
& \times\left[\begin{array}{c}
v_{\mathrm{sf}}^{-} \\
0 \\
0
\end{array}\right]
\end{aligned}
$$

Finally, according to (10), the transformed stator and rotor 212 fluxes are given by (17).

\section{F. Computation of the Reduced-Order Models}

The computation procedure of the proposed reduced-order models is depicted in the block diagram of Fig. 2. Note that the grey rectangle in this figure means that the integration of the dynamic variables has to be done for each reduced-order model separately, not together. Expressions (13) (20) can be represented by the equivalent circuits shown in Fig. 3.

It should be noted from [6] that the first-order model (our R0 model) can be used for small induction machines to determine their dynamic response to load disturbances. However, this is not valid for large induction machines. In general, the first-order model will not yield correct results during the transient operation of machines fed by unsymmetrical voltages.

This aside, the reduced-order models are also valid for either rigid or non-rigid drive-train models [11], thus the obtained models are valid either for two-mass or for one-mass model.

\section{VALIDATION OF THE REDUCED-ORDER MODELS}

\section{A. Voltage Sags}

Unbalanced grid conditions are mainly caused by unsymmetrical voltage sags, which are reductions in the rms grid voltages of one, two three phases during a time interval. According to [17], there exist six types of unsymmetrical voltage sags, namely: B, C, D, E, F and G. In the current paper two voltage sag types have been considered:

1) Sag type D, which can be caused by a two-phase fault after a Dy transformer or by a 1-phase-to-ground fault after two Dy transformers [17].

2) Sag type F, which is caused by a two-phases-to-ground fault after a Dy transformer [17].
215 216 217 218 219 220 221 222 223 224 225 226 227 228 229 230 231 

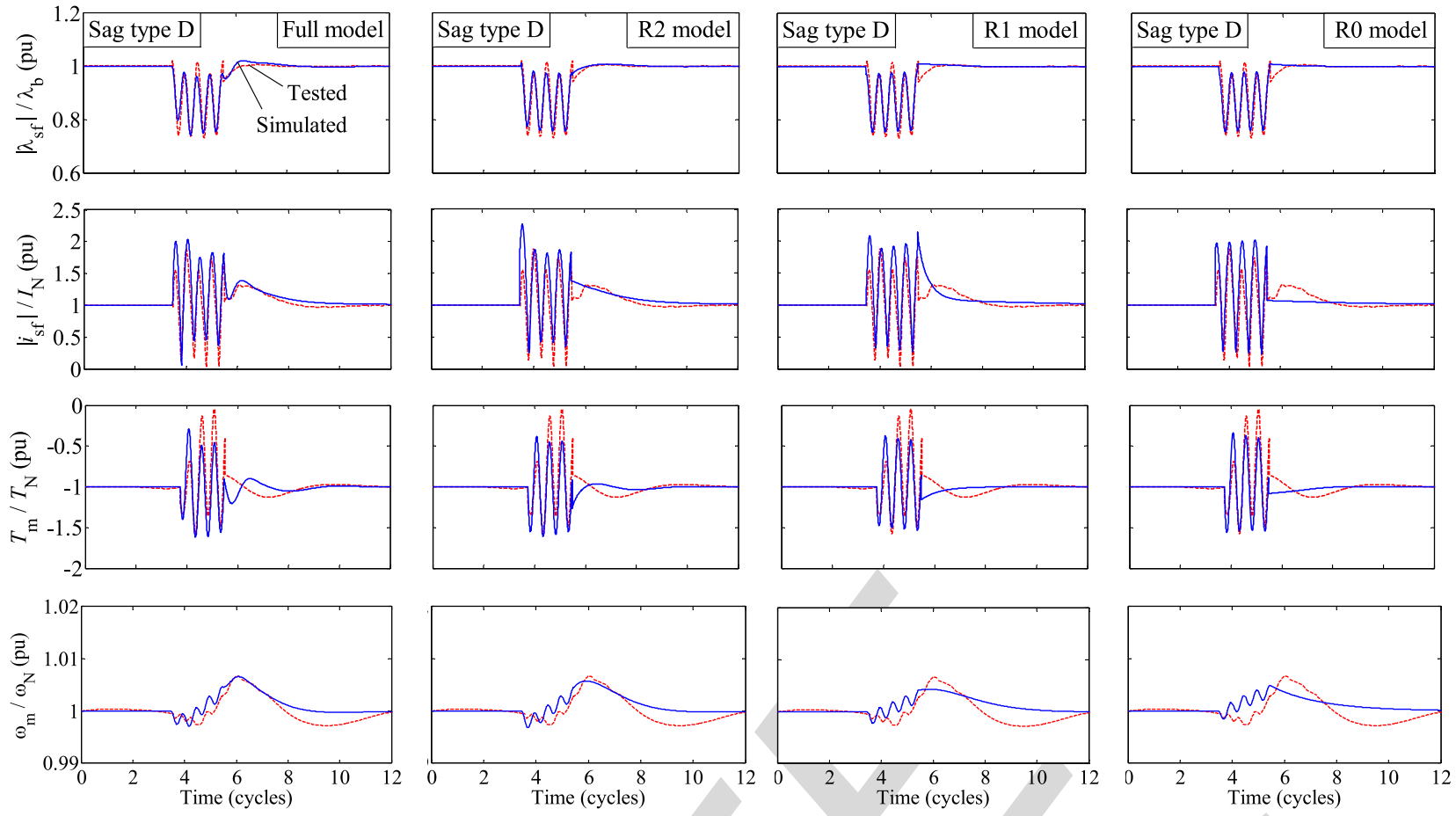

(a)

(b)

(c)

(d)

Fig. 7. $4 \mathrm{~kW}$ squirrel-cage DCIG tested under unsymmetrical voltage sag type D: modulus of the transformed stator flux $\left(\lambda_{\mathrm{sf}}\right)$, modulus of the transformed stator current $\left(i_{\mathrm{sf}}\right)$, electromagnetic torque $\left(T_{\mathrm{m}}\right)$ and mechanical speed $\left(\omega_{\mathrm{m}}\right)$. Comparison with (a) Full-order model, (b) R2 model (usual approach), (c) R1 model (proposed), and (d) R0 model (steady-state). Sag characteristics: $h=0.7$ and $\Delta t=2$ cycles.
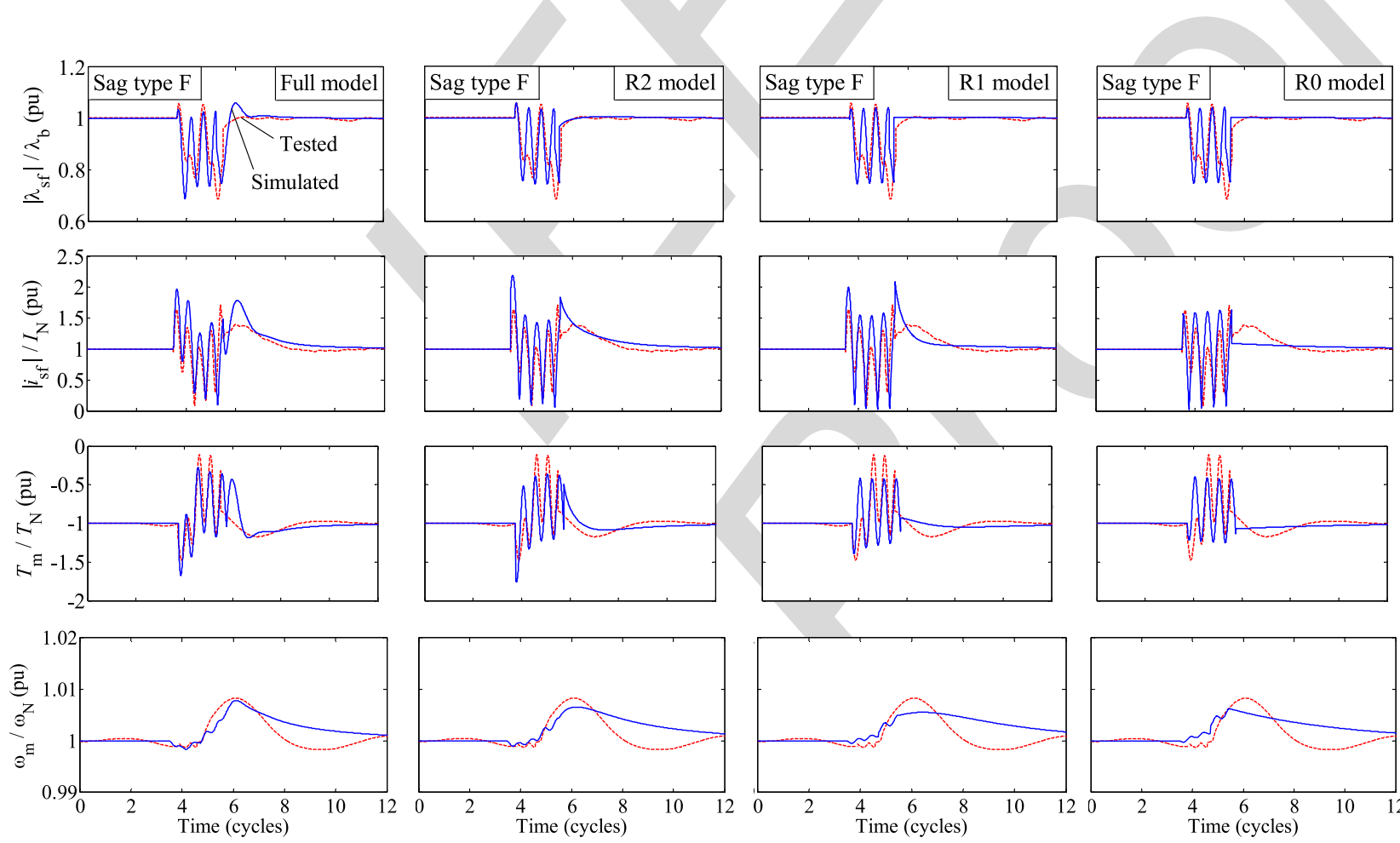

(b)

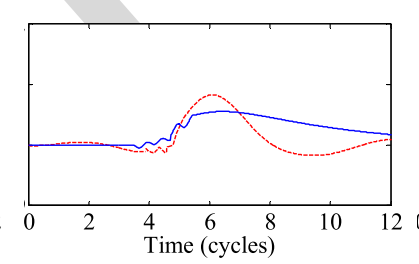

(c)

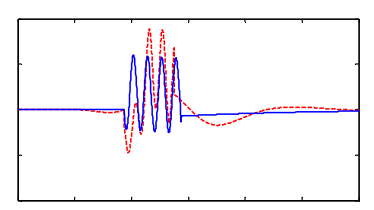

(a)

Fig. 8. $4 \mathrm{~kW}$ squirrel-cage DCIG tested under unsymmetrical voltage sag type F: modulus of the transformed stator flux ( $\left.\lambda_{\mathrm{sf}}\right)$, modulus of the transformed stator current $\left(i_{\mathrm{sf}}\right)$, electromagnetic torque $\left(T_{\mathrm{m}}\right)$ and mechanical speed $\left(\omega_{\mathrm{m}}\right)$. Comparison with (a) Full-order model, (b) R2 model (usual approach), (c) R1 model (proposed), and (d) R0 model (steady-state). Sag characteristics: $h=0.7$ and $\Delta t=2$ cycles. 


\section{B. Simulation Results}

Figs. 4 and 5 show the time evolution of the transformed stator flux, $\lambda_{\mathrm{sf}}$, the transformed inner- and outer-cage rotor fluxes, $\lambda_{1 \mathrm{f}}$ and $\lambda_{2 \mathrm{f}}$, respectively, the electromagnetic torque, $T_{\mathrm{m}}$ and the mechanical speed, $\omega_{\mathrm{m}}$ when the generator is exposed to unsymmetrical sag types $\mathrm{D}$ and $\mathrm{F}$. These sags have been assumed to have a depth $h=0.5$ and a duration $\Delta t=5$ cycles (i.e., $100 \mathrm{~ms}$ considering $f=50 \mathrm{~Hz}$ ). All the simulation results are shown in pu by dividing them by their nominal values, except the fluxes, which are given by:

$$
\begin{aligned}
& \lambda_{\mathrm{sf}}(\mathrm{pu})=\lambda_{\mathrm{sf}} / \lambda_{\mathrm{b}}, \quad \lambda_{1 \mathrm{f}}(\mathrm{pu})=\lambda_{1 \mathrm{f}} / \lambda_{\mathrm{b}}, \\
& \lambda_{2 \mathrm{f}}(\mathrm{pu})=\lambda_{2 \mathrm{f}} / \lambda_{\mathrm{b}}
\end{aligned}
$$

where

$$
\begin{aligned}
& \lambda_{\mathrm{b}}=L_{\mathrm{b}} I_{\mathrm{b}}, L_{\mathrm{b}}=Z_{\mathrm{b}} / \omega_{\mathrm{b}}, Z_{\mathrm{b}}=U_{\mathrm{b}}^{2} / S_{\mathrm{b}} \\
& \omega_{\mathrm{b}}=2 \pi f_{\mathrm{b}}, I_{\mathrm{b}}=I_{\mathrm{N}} .
\end{aligned}
$$

The following observations can be made from Figs. 4 and 5 results:

1) Under unbalanced grid conditions there appear pulsations in all the variables, which correspond to twice the fundamental pulsation. These pulsations are very noticeable in the electromagnetic torque.

2) The reduced-order models reasonably predict the behavior of the machine, as the time evolution of all the variables is similar to the ones of full-order model.

3) Among all the reduced-order models the most simplistic dynamic model, i.e., the R1 model (proposed model) is accurate enough to study the machine behavior under unsymmetrical sags.

4) As the R0 model has no derivative terms in the electrical equations, the information of the DCIG behavior during the voltage sag is lost. It can be clearly seen in the time evolution of both rotor fluxes, which does not correspond with the full-order model. Note also that the oscillation in these variables during the sag is due to the fact that the transients in the mechanical equations have not been neglected. If these transients had been neglected, the time evolution of the stator and rotor fluxes during the sag would have followed a constant line.

\section{Experimental Results}

In order to validate both the analytical study and the simulation results, a real $4 \mathrm{~kW}$ three-phase double-cage squirrel-cage induction generator is tested. Its parameters are given in Table II. The machine has been tested at its nominal operating point, i.e., at $1440 \mathrm{rpm}$. Fig. 6 shows the experimental setup which has been used to test the machine under voltage sags.

As it is a squirrel-cage induction generator, the lecture of the rotor variables was not accessible. Then, only the stator currents and voltages were measured. The stator flux was obtained by numerical integration of:

$$
\mathrm{d} \lambda_{\mathrm{sf}} / \mathrm{d} t=v_{\mathrm{sf}}-R_{\mathrm{s}} i_{\mathrm{sf}}-\mathrm{j} \omega_{\Psi} \lambda_{\mathrm{sf}} .
$$

TABLE III

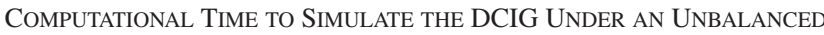
GRID*

\begin{tabular}{lcccc}
\hline \hline & & \multicolumn{3}{c}{ Reduced-order models } \\
\cline { 3 - 4 } Sag type & Full-order model & R2 (usual) & R1 (proposed) & R0 (steady-state) \\
\hline $\mathrm{D}$ & $2.893 \mathrm{~s}$ & $2.645 \mathrm{~s}$ & $2.473 \mathrm{~s}$ & $2.105 \mathrm{~s}$ \\
$\mathrm{~F}$ & $2.815 \mathrm{~s}$ & $2.573 \mathrm{~s}$ & $2.432 \mathrm{~s}$ & $2.101 \mathrm{~s}$ \\
\hline \hline & & & \\
$*$ & Considering: & & \\
$\rightarrow$ A transient of 14 cycles (280 ms). & \\
$\rightarrow$ The 2.3 MW DCIG whose parameters are shown in Table I. \\
$\rightarrow$ Sag characteristics: $h=0.5$ and $\Delta t=5$ cycles. \\
$\rightarrow$ Matlab simulation software using ode45 solver.
\end{tabular}

Figs. 7 and 8 show the time evolution of the modulus of the 290 transformed stator flux, $\lambda_{\mathrm{sf}}$, the modulus of the transformed 291 stator current, $i_{\mathrm{sf}}$, the electromagnetic torque, $T_{\mathrm{m}}$, and the me- 292 chanical speed, $\omega_{\mathrm{m}}$, of the tested induction generator under 293 voltage sag types $\mathrm{D}$ and $\mathrm{F}$. These sags have been assumed to 294 have a depth $h=0.7$ and a duration $\Delta t=2$ cycles (i.e., $40 \mathrm{~ms} 295$ considering $f=50 \mathrm{~Hz}$ ).

In Figs. 7 and 8, the time evolution of the measured variables is compared with the full-order model and the analyzed reducedorder models. It is observed that all the reduced-order models predict accurately the real behavior of the DCIG measured from the stator, as well as the torque and the speed. Among them, the R1 model (proposed model) predicts with good precision the behavior of the machine under unbalanced grid conditions.

Note that the R0 model fails to describe the DCIG behavior, specially when the voltage recovers. As there are no derivative terms in the electrical equations, it is observed that there is almost no transient in both the stator flux and the stator current when the fault is cleared. Indeed, when the sag ends these variables return to the pre-fault steady-state value almost instantaneously (it is not instantaneous at all due to the dynamics in the mechanical equations).

\section{Computational Time and Reduced-Order Model Errors}

Table III shows the computational time required to simulate the full-order model and the reduced-order models of the DCIG. As can be observed, the R1 model (proposed model) is the dynamic model that requires the lowest computational time to simulate the DCIG (the R0 model is the steady-state model, so its computational time is not taken into account).

Fig. 9(a) shows the error in the DCIG simulated variables between the full-order model and the reduced-order models. Fig. 9(b) shows the error in the DCIG variables between the experimental results and the simulated reduced-order models. It is observed that the R1 model (proposed model) has a good accuracy, as the error made with this model is pretty much the same as the error in the standard R2 model.

As a result, between all the reduced-order models, the R1 model (proposed model) appears to be the most suitable one, because it predicts with good accuracy the DCIG behavior under unsymmetrical sags. Moreover, it requires the lowest 92 93 295 

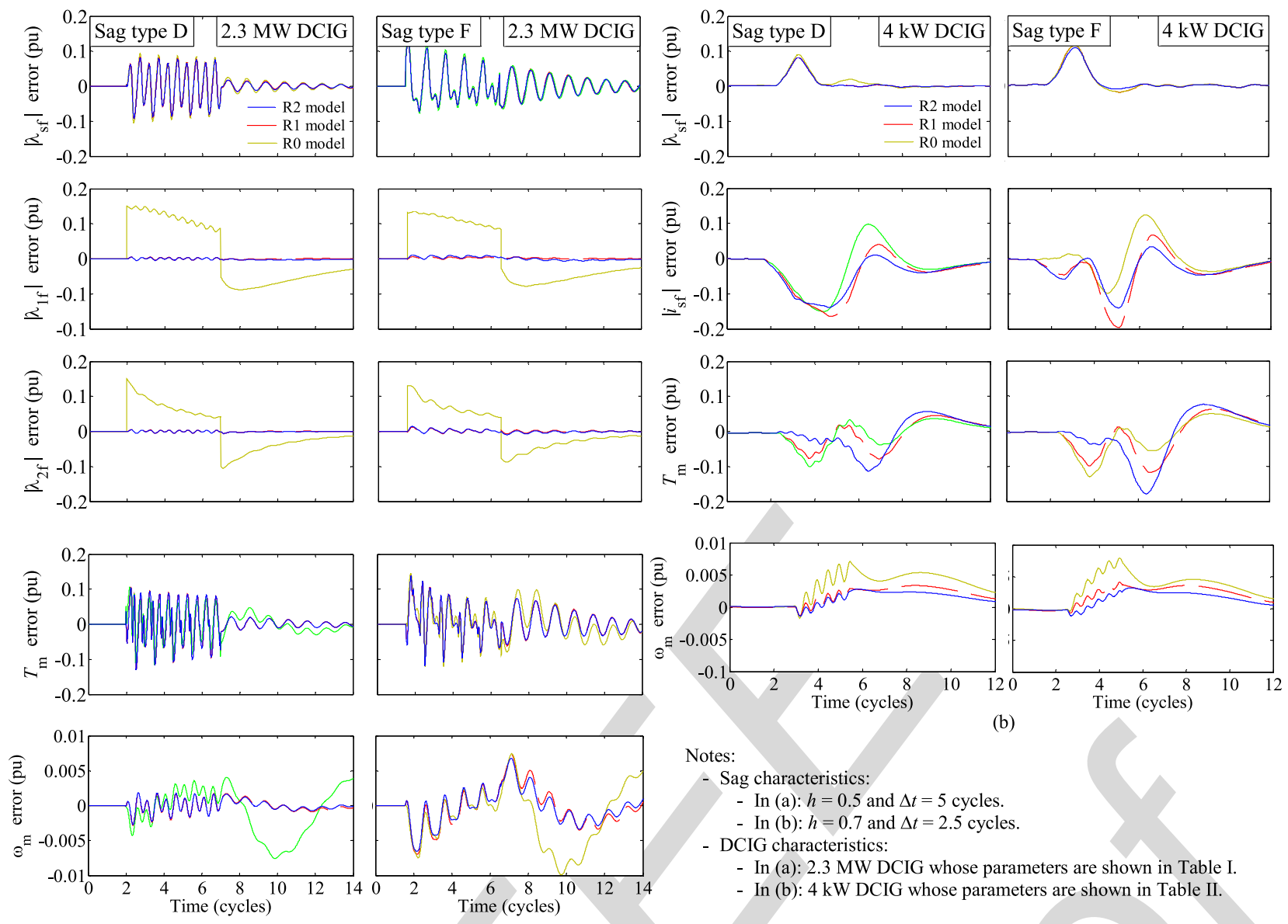

(b)

Notes:

- Sag characteristics:

- In (a): $h=0.5$ and $\Delta t=5$ cycles.

- In (b): $h=0.7$ and $\Delta t=2.5$ cycles.

DCIG characteristics:

- In (a): 2.3 MW DCIG whose parameters are shown in Table I.

- In (b): $4 \mathrm{~kW}$ DCIG whose parameters are shown in Table II.

(a)

Fig. 9. Error in the DCIG variables under unsymmetrical voltage sag types D and F when comparing the different reduced-order models. (a) Error between the fullorder model and the reduced-order models in the simulation results, and (b) error between the experimental results and the simulation results considering the reduced-order models. Solid line $=\mathrm{R} 2$ model (usual approach), dashed line $=\mathrm{R} 1$ model (proposed) and dotted line $=\mathrm{R} 0$ model (steady-state).
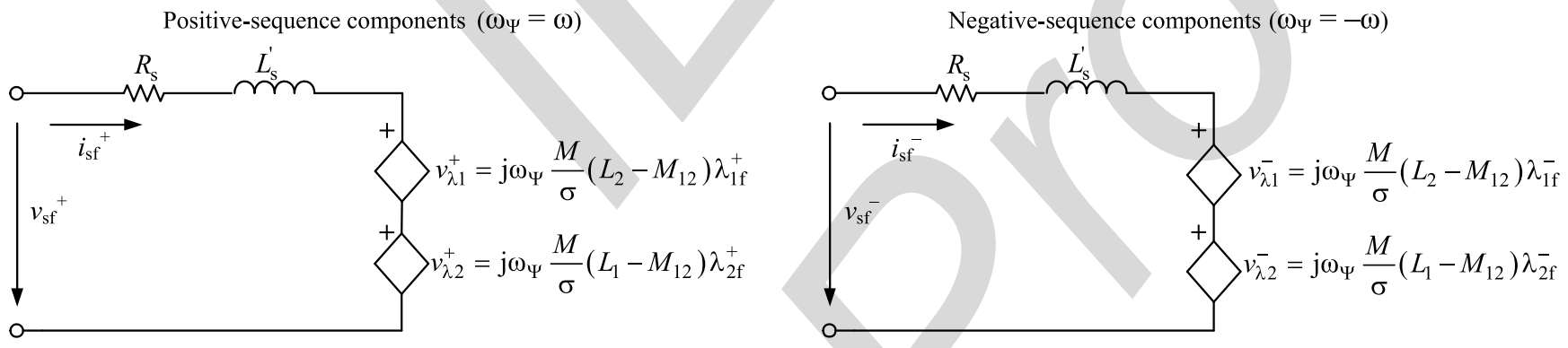

Fig. 10. Equivalent circuits of the DCIG under unbalanced grid conditions considering the compact equations of the reduced-order models.

computational time to simulate the behavior of this machine under unbalanced grid conditions.

\section{E. Final Remarks}

The analytical models have been validated by means of the simulations of a 2.3 MW fixed-speed WT equipped with a DCIG and the experimental tests of a $4 \mathrm{~kW}$ DCIG, considering unbalanced grid conditions caused by sag types $\mathrm{D}$ and $\mathrm{F}$.

The R2 model neglects the transients of both positiveand negative-sequences of the stator fluxes. This is the usual approach in the literature. As observed in the results, it predicts 339 with good accuracy the behavior of the machine under unbal- 340 anced grid conditions. However, it requires the largest compu- 341 tational time.

The R1 model is the author's proposed model. Apart from 343 the transients of the stator fluxes, the transients of the negative- 344 sequences of both inner and outer cage are also neglected. Of 345 course, this model is not as realistic as the R2 model. However, 346 judging by the simulations and test results obtained in this paper, 347 this model predicts accurately the behavior of the machine 348 
under unbalanced grid conditions, as the time evolution of the variables are pretty much the same as the ones in the R2 model. The advantage of this model is that it has more algebraic equations and less differential equations (it only has two differential equations, while the R2 model has four differential equations), so it requires a lower computational time to be simulated.

The R0 model is the electrical steady-state model. Naturally, as all the transients of the electrical variables are neglected (but not the transients of the mechanical equations), this model does not predict the behavior of the machine under unbalanced grid conditions as precisely as the other models.

Then, among all the studied models, the authors propose that the R1 model accurately predicts the behavior of the DCIG under unbalanced grid conditions. It almost does not loose detail of system performance and it has the advantage of requiring a lower computational time than the R2 model.

It should be noted that the models have not been validated under variable wind speed. In this case, the reliability of the reduced-order models would not depend on the models themselves but on the control algorithm, which goes beyond the scope of this paper. Then, an interesting future work could be to use the proposed reduced-order models of DCIG (specially the proposed R1 model) plus a control scheme in order to predict the dynamics of the DCIG when a sudden change in the wind speed occurs.

Finally, it should also be noted that an analysis of the reducedorder models considering different sag durations and depths has not been carried out due to extension purposes. Then, another interesting work to be done in the future would be to study how the reduced-order models behave (specially the proposed R1 model) under unsymmetrical voltage sags with a wide range of durations and depths.

\section{CONCLUSION}

This paper has developed a study of reduced-order models of double-cage squirrel-cage induction generators (DCIG) used in fixed-speed WTs. These models are valid for unbalanced grid conditions.

From the full-order model (fifth-order model) the following reduced-order models have been studied. The $\mathrm{R} 2$ model has been obtained neglecting the derivative of the positive- and negativesequence of the stator fluxes (usual approach in the literature). The R1 model has been obtained neglecting the derivative of the stator fluxes and the derivative of the negative-sequence of the rotor fluxes (proposed model). And the R0 model has been obtained neglecting the derivative of both positive- and negativesequences of the stator and rotor fluxes (electrical steady-state model).

Both simulation and experimental results have shown that the reduced-order models show a good performance (similar to the full-order model) under unbalanced conditions. Among them, the most simplistic dynamic model (the proposed R1 model) shows a good accuracy to predict the behavior of DCIG. Moreover, it requires the lowest computational time to simulate the machine behavior.

\section{APPENDIX I}

\section{A. Analytical Expressions of Voltage Sags}

The Ku transformation relates the abc phase components of a three-phase system to the Ku transformed components, namely zero (0), forward (f) and backward (b):

$$
\left[\mathbf{v}_{0 \mathrm{fb}}\right]=[\mathbf{K}(\Psi)]\left[\mathbf{v}_{\mathrm{abc}}\right] \quad\left[\mathbf{v}_{\mathrm{abc}}\right]=[\mathbf{K}(\Psi)]^{-1}\left[\mathbf{v}_{0 \mathrm{fb}}\right]
$$

The original Ku transformation is defined in [10]. In this paper it is used in the normalized (or power-invariant) form:

$$
[\mathbf{K}(\Psi)]=\frac{1}{\sqrt{3}}\left[\begin{array}{ccc}
1 & 1 & 1 \\
\mathrm{e}^{-\mathrm{j} \Psi} & \mathrm{ae}^{-\mathrm{j} \Psi} & \mathrm{a}^{2} \mathrm{e}^{-\mathrm{j} \Psi} \\
\mathrm{e}^{\mathrm{j} \Psi} & \mathrm{a}^{2} \mathrm{e}^{\mathrm{j} \Psi} & \mathrm{ae}^{\mathrm{j} \Psi}
\end{array}\right],
$$

where $\mathrm{a}=\mathrm{e}^{j 2 \pi / 3}$ and $\Psi$ is the transformation angle. If the 411 synchronous reference frame is considered, then $\Psi=\omega t+\Psi_{0}, \quad 412$ where $\omega=2 \pi f$ is the pulsation of the grid voltages ( $f$ is their 413 frequency) and $\Psi_{0}$ is the transformation's initial angle. $\quad 414$

It should be noted that the backward component, $v_{\mathrm{b}}$, equals 415 the complex conjugate of the forward component, $v_{\mathrm{f}}$. Apart, if 416 no zero component, $v_{0}$, is considered (if the studied equipment 417 has no neutral connections), only the forward component has to 418 be studied, which is:

$$
v_{\mathrm{f}}=\left(v_{\mathrm{f} 1}+v_{\mathrm{f} 2} \mathrm{e}^{-\mathrm{j} 2 \omega t}\right) \mathrm{e}^{-\mathrm{j} \Psi_{0}}
$$

where $v_{\mathrm{f} 1}$ and $v_{\mathrm{f} 2}$ are:

$$
\begin{aligned}
& v_{\mathrm{f} 1}=\sqrt{3 / 2} \underline{V}_{\mathrm{p}}=\sqrt{3 / 2} V_{\mathrm{p}} \mathrm{e}^{\mathrm{j} \alpha_{\mathrm{p}}} \\
& v_{\mathrm{f} 2}=\sqrt{3 / 2} \underline{V}_{\mathrm{n}}^{*}=\sqrt{3 / 2} V_{\mathrm{n}} \mathrm{e}^{-\mathrm{j} \alpha_{\mathrm{n}}},
\end{aligned}
$$

where $V_{\mathrm{p}}$ and $V_{\mathrm{n}}$ are the rms value of the positive- and negativesequence voltages of sags and $\alpha_{\mathrm{p}}$ and $\alpha_{\mathrm{n}}$ are their angles. Then, (26) can be expressed in terms of the positive- and negativesequence voltages as:

$$
v_{\mathrm{f}}=\sqrt{3 / 2}\left(V_{\mathrm{p}} \mathrm{e}^{\mathrm{j} \alpha_{\mathrm{p}}}+V_{\mathrm{n}} \mathrm{e}^{-\mathrm{j}\left(2 \omega t+\alpha_{\mathrm{n}}\right)}\right) \mathrm{e}^{-\mathrm{j} \Psi_{0}} .
$$

The transformed Ku forward component $\left(x_{\mathrm{f}}\right)$ is a complex notation of the Park dq components [10]:

$$
x_{\mathrm{d}}=\sqrt{2} \operatorname{Re}\left(x_{\mathrm{f}}\right) \quad x_{\mathrm{q}}=\sqrt{2} \operatorname{Im}\left(x_{\mathrm{f}}\right) .
$$

\section{APPENDIX II}

\section{B. Electrical Equations of the DCIG Written in a More} compact Form

Equations (13)-(20) can be written in a more compact form. The R2 model for the electrical equations of the DCIG is obtained when assuming a constant stator flux, i.e., neglecting the differential term of the stator flux in (1), which results in:

$$
\begin{aligned}
v_{\mathrm{sf}} & =R_{\mathrm{s}} i_{\mathrm{sf}}+\mathrm{j} \omega_{\Psi} \lambda_{\mathrm{sf}} \\
0 & =R_{1} i_{1 \mathrm{f}}+\frac{\mathrm{d}}{\mathrm{d} t} \lambda_{1 \mathrm{f}}+\mathrm{j}\left(\omega_{\Psi}-p \omega_{\mathrm{m}}\right) \lambda_{1 \mathrm{f}} \\
0 & =R_{2} i_{2 \mathrm{f}}+\frac{\mathrm{d}}{\mathrm{d} t} \lambda_{2 \mathrm{f}}+\mathrm{j}\left(\omega_{\Psi}-p \omega_{\mathrm{m}}\right) \lambda_{2 \mathrm{f}} .
\end{aligned}
$$




$$
\begin{aligned}
L_{\mathrm{s}}^{\prime} & =\left(L_{\mathrm{s}}+\frac{M^{2}\left(2 M_{12}-L_{1}-L_{2}\right)}{\sigma}\right) \\
v_{\lambda 1} & =\mathrm{j} \omega_{\Psi} \frac{M}{\sigma}\left(L_{2}-M_{12}\right) \lambda_{1 \mathrm{f}} \\
v_{\lambda 2} & =\mathrm{j} \omega_{\Psi} \frac{M}{\sigma}\left(L_{1}-M_{12}\right) \lambda_{2 \mathrm{f}} .
\end{aligned}
$$

440 441

By substituting (32) in the rotor equations in (1) and grouping 1 terms, we obtain:

$$
\begin{aligned}
\frac{\mathrm{d}}{\mathrm{d} t} \lambda_{1 \mathrm{f}} & =-A \lambda_{1 \mathrm{f}}-\mathrm{j}\left(\omega_{\Psi}-p \omega_{\mathrm{m}}\right) \lambda_{1 \mathrm{f}}+B \lambda_{2 \mathrm{f}}-C i_{\mathrm{sf}} \\
\frac{\mathrm{d}}{\mathrm{d} t} \lambda_{2 \mathrm{f}} & =-D \lambda_{2 \mathrm{f}}-\mathrm{j}\left(\omega_{\Psi}-p \omega_{\mathrm{m}}\right) \lambda_{2 \mathrm{f}}+E \lambda_{1 \mathrm{f}}-F i_{\mathrm{sf}}
\end{aligned}
$$

442 where

$$
\begin{array}{lll}
A=\frac{R_{1} L_{2}}{\sigma} & B=\frac{R_{1} M_{12}}{\sigma} & C=\frac{R_{1} M}{\sigma}\left(L_{2}-M_{12}\right) \\
D=\frac{R_{2} L_{1}}{\sigma} & E=\frac{R_{2} M_{12}}{\sigma} & F=\frac{R_{2} M}{\sigma}\left(L_{1}-M_{12}\right) .
\end{array}
$$

Then, the R2 model of the DCIG is given by (33)-(36). Note that this model should be applied for the positive- and negativesequences of the DCIG variables.

If the transients of the negative-sequence of both inner and outer cages are neglected in (35), the R1 model (proposed model) is obtained.

Finally, if the transients of all the machine's fluxes are neglected, the R0 model (electrical steady-state model) is obtained. Note that (33)-(36) can be represented by the equivalent circuits shown in Fig. 9 (for the positive- and negative-sequence components), where the difference between R2, R1 and R0 models lies in considering (or not), de derivative of the fluxes, i.e., considering (or not) the dependent voltage sources.

\section{REFERENCES}

[1] F. Córcoles, Ll. Monjo, S. Bogarra, and A. Rolán, "On fixed-speed WT generator modeling for rotor speed stability studies," IEEE Trans. Power Syst., vol. 27, no. 1, pp. 397-406, Feb. 2012.

[2] H. Martín, J. de la Hoz, Ll. Monjo, and J. Pedra, "Study of reduced-order models of squirrel-cage induction motors," Elect. Power Compon. Syst., vol. 39, no. 14, pp. 1542-1562, Oct. 2011.

[3] P. Kundur, Power Systems Stability and Control. New York, NY, USA McGraw-Hill, 1994, pp. 93-100.

[4] O. Wasynczuk, D. Yi-Min, and P. C. Krause, "Theory and comparison of reduced order models of induction machines," IEEE Trans. Power App. Syst., vol. PAS-104, no. 3, pp. 598-606, Mar. 1985.

[5] N. A. Khalil, O. T. Tan, and I. U. Baran, "Reduced order models for doublecage induction motors," IEEE Trans. Power App. Syst., vol. PAS-101, no. 9, pp. 3135-3140, Sep. 1982

6] P. Vas, Electrical Machines and Drives. A Space-Vector Theory Approach. 471 Oxford, U.K.: Oxford Univ. Press, 1992, pp. 234-238.

[7] P. C. Krause, O. Wasynczuk, and S. D. Sudhoff, Analysis of Electric 473 Machinery and Drive Systems, 2nd ed. Piscataway, NJ, USA: IEEE Press, 474 2002, pp. 313-318.

[8] G. G. Richards and O. T. Tan, "Simplified models for induction machine transients under balanced and unbalanced conditions," IEEE Trans. Ind. Appl., vol. 17, no. 1, pp. 15-21, Jan./Feb. 1981.

[9] R. H. Park, "Two-reaction theory of synchronous machines-Generalized method of analysis, Part I," AIEE Trans., vol. 48, no. 3, pp. 716-727, Jul. 1929.

[10] Y. H. Ku, "Rotating-field theory and general analysis of synchronous and induction machines," Proc. IEE-Part IV: Inst. Monographs, vol. 99, no. 4, pp. 410-428, Dec. 1952.

[11] V. Akhmatov, H. Knudsen, and A. H. Nielsen, "Advanced simulation of 485 windmills in the electric power supply," Int. J. Elect. Power Energy Syst., vol. 22, no. 6, pp. 421-434, Aug. 2000.

[12] S. M. Muyeen, Md. H. Ali, R. Takahashi, T. Murata, J. Tamura, Y. Tomaki A. Sakahara, and E. Sasano, "Comparative study on transient stability anal- 489 ysis of wind turbine generator system using different drive train models," 490 IET Renew. Power Gener., vol. 1, no. 2, pp. 131-141, Jun. 2007.

[13] G. Ramtharan, N. Jenkins, O. Anaya-Lara, and E. Bossanyi, "Influence 492 performance of FSIG and DFIG wind turbines," Wind Energy, vol. 10, 494 no. 4, pp. 293-301, Jul. 2007.

[14] G. Michalke, "Variable speed wind turbines-Modelling, control, and im- 496 pact on power systems," Ph.D. dissertation, Dept. Renew. Energy, Tech- 497 nische Univ. Darmstadt, Darmstadt, Germany, Apr. 2008.

[15] S. Heier, Grid Integration of Wind Energy Comversion Sys Hoboken, NJ, USA: Wiley, 2006, pp. 34-35. W. Kling, "Representing wind turbine electrical generating systems in fundamental frequency simulations," 502 IEEE Trans. Energy Convers., vol. 18, no. 4, pp. 516-524, Dec. 2003.

[17] M. H. J. Bollen, Understanding Power Quality Problems: Voltage Sags 504 and Interruptions. Piscataway, NJ, USA: IEEE Press, 2000, pp 174-198. 505

Authors' biographies not available at the time of publication. of rotor structural dynamics representations on the electrical transient 493

\section{2} 53 454 455 sis 461 62 463 64 5 66
67 68 69 71
72 473
474
475 475 77
78 478 49
480
481 482 483 .

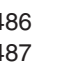
8 0 93 95 99 98 00 02 